\title{
Application of Intelligent Agents in Wireless Prepaid Energy Meter
}

\author{
Suresh Sankaranarayanan \\ Department of Information Technology, SRM University, Kattankaluthur, Tamilnadu-603203 \\ E-mail: suresh.sa@ktr.srmuniv.ac.in, pessuresh@hotmail.com \\ Au Thien Wan and Nurafifah binti Sait \\ School of Computing and Informatics, Institut Teknologi Brunei, Brunei Darussalam \\ E-mail: twan.au@gmail.com and fifahsait@gmail.com
}

\begin{abstract}
Prepaid meter (PM) is getting very popular especially in developing countries. There are many advantages to use prepaid meter as opposed to postpaid meter both to the utility provider and to the consumer. Brunei has adopted PM but it is not intelligent and not wireless enabled. Reading meters and topping up balance are still done manually. Utility provider does not have information on the usage statistics and has only limited functionalities in the grid control. So accordingly an intelligent agent based wireless prepaid energy meter been developed using JADE-LEAP Agent development kit allowing agent from utility provider to query wireless energy meter for energy values for every household. These statistics can be used for statistical computation of the power consumed and for policy and future planning. Agent from consumers' mobile devices can query the energy meter to study the power consumed and for topping up the balance. When the meter reaches the threshold, agent at energy meter would also send messages to alert consumers for topping up through mobile handset and failing to do so will lead to power being cut automatically
\end{abstract}

Index Terms-Wireless Prepaid Smart Meter, JADE, LEAP, Prepaid Meter.

\section{INTRODUCTION}

The traditional method of electricity billing system involves meter reader to periodically visit every house to take readings. There are many issues to this method such as taking wrong readings, lack of meter readers, houses in very remote areas, meters in secluded area in a house and so forth. Towards this many technological advancement have been carried out and one such is employing software agent replicating human beings to collect energy values by means of power line communication [1]-[5]. In some cases wireless technologies are used where energy meter embedded with Zigbee sensor making it wireless accessible for retrieving energy values for billing [6]-[11] and some even employ GPRS for retrieving the energy units for billing from Zigbee based wireless remote meter [12].
In addition to postpaid energy meter access for billing using technologies, there has been research in using GSM based prepaid wireless energy meter where GSM communication is used [13]-[15] for reading energy meter values by power utility to recharge and in some cases to disconnected power supply. The energy meter is embedded with prepaid card equivalent to SIM card used in mobile, which communicates with power utility system using GPRS.

In Brunei Darussalam Prepaid Meter (PM) started to roll out its deployment in the early 2011 and in the following year all tariff were switched to prepaid metering system. And by 2014, all existing post-paid metering system was switched to PM. Presently, the users of PM must monitor and check their electricity usage and balance constantly. So that when the balance is low they are able to buy top-up amount through many outlets across the nation: many branches of Department of Electrical Services (DES), dedicated shops (throughout in the country), through DES website and through hand phone Short Message Services (SMS).

There are many advantages to use PM both to the utility provider and to the consumers. To the utility provider, DES, this reduces tremendously many issues arise from meter readers such as delays, wrong meter readings, infrequent meter reading resulting in bulk amount of billing that consumers would need to pay and further consequent in not paying, disputes and so forth. One of the main motivation of using PM is energy conservation. Brunei Darussalam is very actively heading towards achieving energy conservation and the introduction of PM is one of the initiatives. In 2012 the total electrical power usage in the housing sector was $1,879 \mathrm{GWH}$, which was a reduction of 12.4 per cent compared to the total usage in 2011, which was 2,145 GWH. The total cost saving as a result was 30 million Brunei dollars

However, PM does have inherent problems such as consumers need to check their energy consumption by directly inspecting meter to see how much energy is left. PM does have alert system and it alerts the consumers when the energy balance is low by highlighting the reading in red and sending out low beeping sound intermittently. In some cases, the consumers failed to notice the alerts due to going overseas, busy at work, 
meters in secluded locations in the house and others. Consequently the electricity supply to their house was cut off without further warning when the balance reached zero causing a complete blackout and in some occasion causing serious inconveniences to them. PM does not have wireless feature for meter reading and the DES does not have real time information on how much energy units are consumed, balance units for each household and how much users spend on energy units monthly. The users are unable to monitor their energy usage on a regular basis wirelessly for other useful functionalities too.

Based on the current gaps and the motivations in relation to using a Wireless Prepaid Meter (WPM), we developed an initial prototype of Smart Agent based Wireless Prepaid Meter (SAWPM) using JADE-LEAP agent development kit [18]-[20]. This research does not concentrate on wireless prepaid meter design but on development of smart agent in wireless prepaid meter for utility provider and consumers. The system here communicates by means of agents mimicking the job of human to collect the balance from meters periodically for consumers and utility provider. The agent at user's mobile device communicates with the meter to get balance and units consumed. The user will also be notified once the balance is low for topping and also an alert message once user topped from their mobile. All these communication happens by means of JADE-LEAP agents stationed at utility provider, meters and user's mobile as a multi agent system.

The rest of paper is organized as follows. Section II provides some background research survey related to energy meter. Section III details the system architecture of Smart Agent based Wireless Prepaid Meter (SAWPM). Section IV describes the energy meter simulating energy values consumed for household. Section V shows the functionalities of DES agent at the energy department. Section VI shows agent in Wireless Prepaid Meter (WPM). Section VII shows the agent functionalities in User's Android Mobile handset. Section VIII concludes the paper with future work.

\section{LITERATURE SURVEY}

\section{A. Agent based Remote Energy Meter}

The first pioneering research work that was done [1] using software agents have been used to access these energy meters in the house remotely for recording the units used and accordingly the amount calculated. These agents have been developed in Java-RMI. The agent then replicates the human agent who visits the house to read the meter.

The above research was carried out in using Java agents for accessing remote energy meter reading. Research was further done in developing agents for remote energy meter reading for billing, where Energy department server is connected to domestic clients by means of the power line [2].

With this as background, before going into the details of software agent based energy meter reading by means of power line communication, we will see how analog meters functions and their disadvantages.

Presently in many developing countries still analog meters are being used where energy meter readings are computed by counting the number of revolutions of an aluminum disc, which rotates at a speed proportional to the power. The energy consumption is thus proportional to the number of revolutions of the disc.

The main disadvantage of such an analog energy meter is that it does not provide digital data needed to make energy management decisions directly. Analog meter lacks stability and the reading accuracy drifts over a long period of time or if they are installed in environments that experience large temperature shifts. In this context, electronic measurements are more robust and accurate under such conditions. In order to be cost effective, the existing energy meter can also be fitted with a digital read out device, without getting replaced by a digital electronic energy meter. It may be mentioned here that digital electronic energy meters have outperformed the electromechanical analog meters in terms of functionality and performance. The benefits of electronic energy meters are summarized as follows:.

- $\quad$ Processing data for billing benefits the consumers to have lower electricity bills.

- Power outages can be detected, identified, and corrected more quickly.

- Electronic measurements are more accurate and robust compared to electromechanical meters

- Customer service is improved through more efficient power distribution and data management.

So if we can get a digital read out of the energy meter reading without changing the existing installation of energy meter, and transmit the reading through say, the power line, making the process cost effective, it will be a tremendous breakthrough in remote energy metering. For the digital readout of the energy meter reading, the following techniques were proposed. In the first technique proposed [19][20], an optical sensor detects the revolution of the disc in the existing analog type meters. A microcontroller, through this optical sensor, counts the number of revolutions of the disc and stores it in a memory. This data is then displayed or used for further processing. This in essence, is the functioning of the digital readout device as an attachment to the existing analog energy meters. In the second technique proposed [2][21][22], ADE 7751 - a single phase energy metering IC chip, is used for computing the power consumed. Essentially the IC chip enables the multiplication of the voltage and current values and integrates the same over a period. The digitized value of the output is then stored for billing purpose.

With this digital meter read out from the analog meter, a software agent has been employed to move from the energy department to the domestic energy meter which then picks up the energy meter data and comes back to the energy department for lodging the data [5]. While sending the software agent through the power line for fetching the energy meter data, the date and time are 
noted and hence the data brought in by the agent has the date and time stamp also, since a software agent making a single trip, does not consume much time. Since the server in the energy department can control many clients (domestic energy meters), it is possible for one software agent (like a human agent) to visit a fairly good number of clients and bring the set of energy meter data back to the server in the Energy department. The software agent will be invoked once in every month and the agent travels through all the clients, and collects the requested data for the server. All such collected details will then be stored in the database of the server. The values of the variables or the data in the database will be updated continuously every month. After storing the data as above the amount to be paid will then be calculated at the server. The amount details will then be delivered to the clients for paying [3].

When the number of clients attached to a single server (EB office) becomes enormous, it is prudent to use multiple agents to do the same functions towards avoiding over loading of the single software agent, due to lack of memory space and to follow decentralized approach. The entire area to be covered using multiple agents, say, is decentralized as north, south, east and west zones, where each zonal client readings are captured by a respective individual agent. The customers in any particular area will then come in any one of the above zones according to their addresses. This technique is used so that all the agents will have equal task to be performed, and thus the load is balanced. The server initiates the data capture agent to capture the data (meter reading) from their respective clients in its zone. The collected details will be stored in the signaling agent's database. The signaling agent signals the server asking whether the server is free or not. If the server is free the signaling agent requests the server to send the congestion control agent to collect all the captured meter readings. The server sends the congestion control agent which navigates to the signaling agent, collects all the captured data (meter reading) and reports to the server. Thus intelligently congestion is also avoided using agent technology. The recently updated value will be given to the server side administrator, whenever the client wishes to retrieve the data by providing the proper customer ID, and zone. It is a must to fill the client number provided by the electricity board, to connect the server with the client [4]. During employing agents to retrieve meter values, security is a main challenge which needs to be taken care of. So accordingly security tools are used to attain confidentiality, integrity, availability and accountability (logging) of the power meter readings collection process[6].

\section{B. Wireless Remote Energy Meter}

In the Sultanate of Oman, a model of Wireless Automatic Meter Reading System (WAMRS) has been developed [7] in which the wireless communication is based on IEEE 802.15.4 (ZigBee) standard and security is implemented by following the Direct Sequence Spread Spectrum (DSSS) protocol. Successful demonstration of
WAMRS prototype has made it possible to be implemented in Oman on a larger scale for meter reading applications. The main goal of this research was to send periodical readings of an electricity meter wirelessly to a server in the billing office of the electricity supply company. There were central points covering each geographical area, since each premises unit would have limited range of wireless coverage, while the central points would have long-range wireless transmitters that could deliver the meter-reading data over long distances to the billing office. The server in the billing office had a highly secure database system which enabled authorized staff members of the electricity supply company to read and print electricity bills. For premises out of the coverage area of any central point, the solution proposed was to make the nearest premises unit (covered by a central point) as the central point for such remote premises. This added a constraint on the wireless device used for such purpose because such a device should have the capability of both sending and receiving the data. Bill generation software has been programmed using Visual Basic/Macromedia Flash MX, interfaced to a SQL database server [7].

With the development of wireless communication technology, in recent years there comes requirement for low cost equipment of wireless networking technology, called ZigBee. It is a short range, low-complexity, low cost, low power consumption, low data rate two-way wireless communication technology with high network capacity, short time delay, and it is safe and reliable. Its main application areas include industrial controls, consumer electronics, car automation, agriculture automation, and medical equipment control. The core of this technology is established by IEEE 802.15.4 Working Group, and the ZigBee Alliance founded in 2002 is responsible for high-level applications, interoperability testing, and marketing (Zigbee).

It may now be mentioned that the main methods of metering seen in many developed and developing countries are manual meter reading, IC Card prepaid meter, wire-line and wireless meter reading system. Manual meter reading has been there for decades, but with the implementation of one home one meter, drawbacks of this method of reading are many folds, for instances, difficulty in entering home, low efficiency of fee settlement and so forth. Along with the development electronic technology, IC card prepaid meter, which uses pay-before use, favors the management sector. Since it does not need meter reading on site, partially solves the problem of manual meter reading because. But some problems still exist in the actual operation process: IC card meter is easily damaged due to its direct contact with user and no real-time monitoring. It also fails to avoid theft, damage, and fault of meter. Wire-line metering control system has the advantage of IC card, and at the same time can take full advantage of telephone network, power line network, a cable TV network, and RS-485 bus net, etc. It enables real-time metering, real-time monitoring, and real time control, and can also detect equipment damage, illegal use, etc. But there are some 
issues like cable piping, wiring, etc., which needs to design in advance. In addition, it also has problems with old buildings which do not have pre-designed cable conduit, high installation cost and maintenance cost and also expansion due to system upgrade and issues of compatibility with other network could be expensive.

ZigBee wireless meter reading [11] refers to the use of short range wireless communication technology and computer network technologies to read and process metering data automatically. Wireless automatic meter reading technology can not only save human resources, but more importantly may improve the accuracy by having real time reading of the meter, enabling management sector to access to data messages timely and accurately. The elimination of cable wiring can save human and material resources, so investment is considerably economical. Wireless communication links can be quickly built, engineering cycle significantly shortened, and has better scalability compared to a wireline system [8][10]. If a fault occurs, one only needs to check the wireless data module, and then restore the system back to normal operation [23]. It enables management sector to timely and accurately access power consumption messages.

In another research Automatic Power Meter (APM), the APM is implemented using an Automated Remote Meter (ARM) and Zigbee Based power meter Communication Module. The design presents a new methodology for avoiding the high construction and maintenance costs in the existing meter reading technology. Using an APM with network technologies has become a trend today. If the consumer doesn't pay the bill in time, the power connection will be disconnected from the remote server automatically. It displays the corresponding billing information on LCD and sends data to the server through the Zigbee Module. The ARM based hardware system consists of a processor core board and the peripheral board. The entire programming is based on Embedded C Language. This system provides efficient meter reading, avoiding the billing error and reduces the maintenance cost [24].

In yet another research GPRS communication has been used to retrieve meter values from Zigbee Wireless remote meter of water, electricity and gas towards computation. This system is low cost and has low power consumption, while it has great extension and security. It can be used in other areas widely [12].

\section{Wireless Prepaid energy Meter}

In one of the research, a microcontroller based single phase digital Prepaid Energy Meter has been developed using two microcontrollers from the Atmel AVR family and an Energy Meter IC. Also a credit card is used which is capable of communicating with both the distributor unit from where the credit card have to be recharged and the energy meter to which the number of recharged units to be loaded. An electronic circuit called USB burner circuit is used to load the recharged units both in energy meter and smart card. Software have been developed in C-language and compiled by Win-AVR Libc compiler.
The proposed energy meter has been implemented in the laboratory and final results obtained have been presented and compared with electromechanical energy [25].

In one another research a GSM-based Energy Recharge System for prepaid metering has been developed for Nigerian Power Sector towards the metering and billing system. GSM-based Energy Recharge Interface contains a prepaid card equivalent to a mobile SIM card. The prepaid card communicates with the power utility using GSM communication network. Once the prepaid card value has reached zero, the consumer load is disconnected from the utility supply by the latching relay (contactor). The power utility can recharge the prepaid card remotely through GSM/SMS mode based on customers' requests. GSM-Based Recharge System (GBRS) for single-phase prepaid meter has been modeled and simulated in Matlab/Simulink environment [14].

Similar to the above, a prepaid energy meter has been developed for India, on the account of high percentage of electricity revenue being lost to power theft, incorrect meter reading and billing, and reluctance of consumers towards paying electricity bills on time. In this system prepaid card is also present similar to mobile phone SIM card which communicates with electricity department server by means of mobile communication infrastructure. It allows consumers to recharge the energy meter from their mobile phone too. Also once card balance is out, the consumer load is disconnected from the utility supply by the contactor [13].

In prepaid energy meter, the GSM module serves to provide a mode of communication between the user/meter and the EB Station. A user would then be able to carry his/her electricity account with him, eliminating the need to set up a new account every time the user changes homes. The GSM module will also get real time electricity rates and enable the utility to keep a check on electricity theft. This can also be applied in institutions/companies for creating awareness for saving energy among employees. This is in addition to recharging electricity unit from home by user's from their mobile handsets [15].

\section{SMart Agent BASEd WIRELESS PREPAID MEter ARCHITECTURE}

The Smart Agent based Wireless prepaid meter architecture [16] consists of three modules; the first is the wireless energy meter that can generate units consumed by the energy meter which is used further for the calculation of every data. The second handles energy monitoring tasks which includes data such as balance units and total top up amount at Department of energy. The later will handle the exchange of values between devices for querying tasks from user's mobile handset in providing continuous transfer of balance units, top-up amount, in addition to triggering the alert system when the units hit a certain threshold amount. Fig 1 shows the overall architecture design of a Smart Agent Based Prepaid Wireless Energy Meter System. The architecture design consists of four main modules: 
- Energy meter simulator can generate energy units consumed by the household which is used further for the calculation of balance units and for subsequent actions at the Wireless energy meter as a replacement of physical energy meter.

- The JADE Agent Main container for DES which can destroy or combine all active agents in the same environment serving its purposes.

- JADE-LEAP Agent [17][18] for Zigbee enabled Wireless Energy meter.

- JADE-LEAP Agent [17][18] for User Android Application for monitoring and querying balance units wirelessly. And also handle the exchange of values between devices for the querying tasks

\section{A. System Architecture Design}

The system architecture shown in Fig.1 is aimed to support both the JADE Agents platform and modules of the proposed system in the best possible way, involving all JADE Agents implemented devices and the position of databases in the given environment.

The system started with the energy simulator generating values for energy consumption. These values are saved and will be used for balance unit calculations in wireless energy meter. The values are then supplied to the wireless energy meter and further to all active JADE agent devices as shown in Fig.1. The DES backup database will become the medium of displaying data into the DES. This is to ensure precise updated records such as units consumed, balance units and total top up for each meter to be revised every 5th of every month. The User Android application and wireless energy meter required logins before entering the system. This is to ensure security authentication for the system

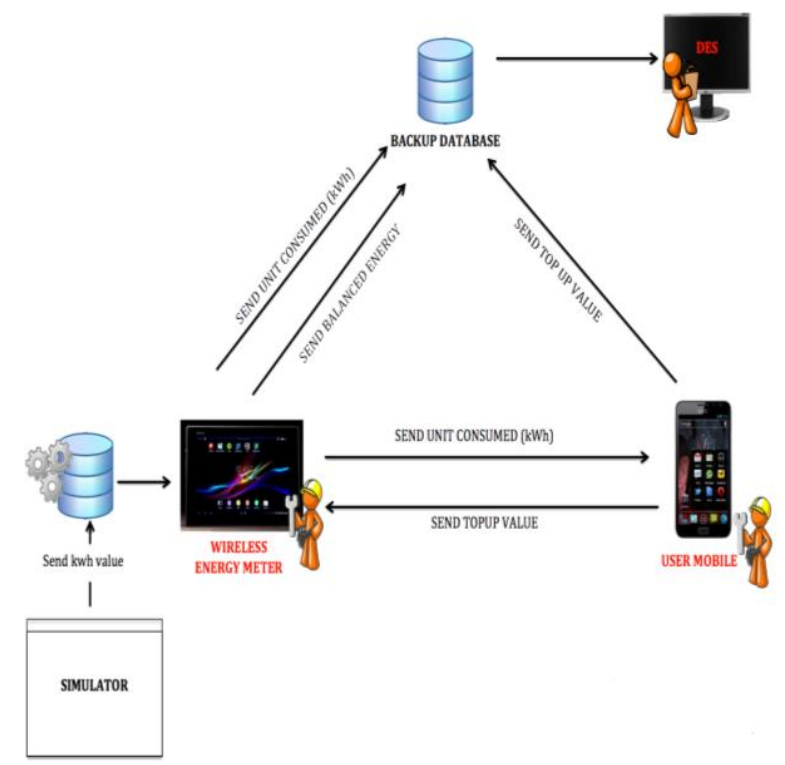

Fig.1. Agent based Wireless Smart Prepaid Meter System Architecture

\section{B. System Database}

There are two different databases involved in this system:

\section{Energy Meter database}

The purpose of this is to store following information as shown in Fig 2:

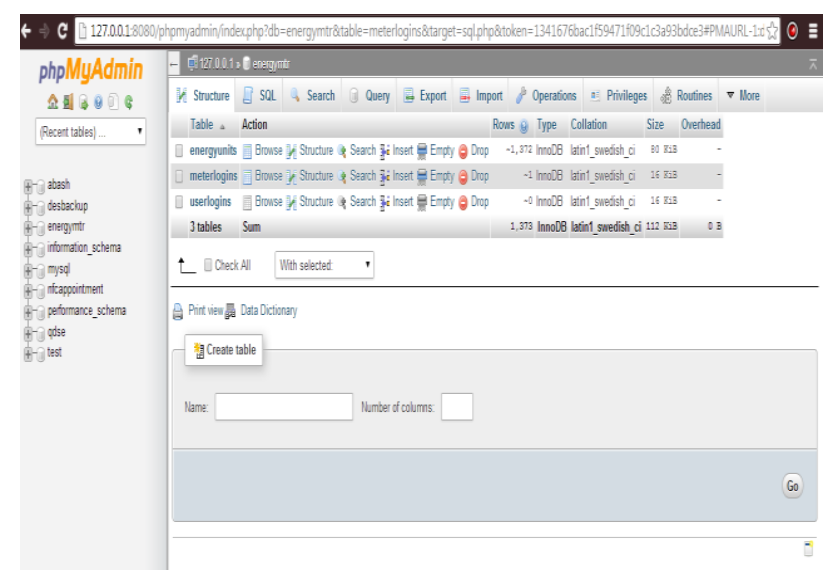

Fig.2. Database tables for Wireless Energy Meter and User Android

- Login information for both energy meter and user Android applications (user logins and meter logins table).

- Units consumed generated by the energy meter simulator (energy units table).

- Data for balance unit calculations

The energy consumption values generated is according to the daily appliances usage of each household and their peak and off peak hour values from Department of Electrical Service Brunei.

\section{DES Backup Database}

This database is for back up any data sent from the user Android application for the calculation of total top-up amount and from the wireless energy meter balance units. These values will only be displayed on DES main page every $5^{\text {th }}$ of every month for monitoring purposes. The table contains these values as shown in Fig.3

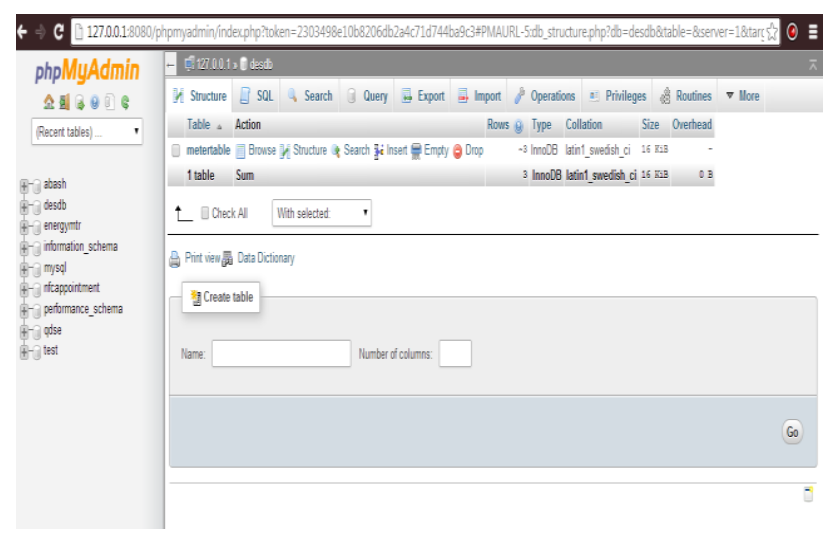

Fig.3. Database for Department of Electrical Services

- Meter number of each household.

- Timestamp

- Balance units.

I.J. Intelligent Systems and Applications, 2016, 3, 66-76 
- Top-up amount

- Total top-up amount

\section{IMPLEMENTATION OF ENERGY METER SiMULATOR}

Based on previous work [26] the energy simulator was implemented using JAVA language. Similar to daily energy consumption and current energy meter, the simulator have the features for peak and off-peak hour, the energy units that has been consumed as well as giving a graphical indication of the time and day.

The Energy simulator periodically generates the energy consumption units according to the data and information given by the DES and Singapore Power (Singapore utility provider) as shown in Table 1. Once the units are generated, the values are merged with the peak and offpeak hours given by DES. The resulting energy consumption units generated by wireless energy meter simulator are shown in Table 2

Table 1. Peak and Off Peak Hours

\begin{tabular}{|c|c|}
\hline APPLIANCES & $\begin{array}{c}\text { UNITS CONSUMED DAILY } \\
\text { IN KWH }\end{array}$ \\
\hline Air-Conditioner & 288 \\
\hline Aquarium & 5 \\
\hline Ceiling Fan & 21 \\
\hline Hair Dryer & 24 \\
\hline Computer & 27 \\
\hline Laptop & 9 \\
\hline Lightings ( 3 units) & 10 \\
\hline Radio & 1 \\
\hline Refrigerator & 96 \\
\hline Rice Cooker & 54 \\
\hline Vacuum & 59 \\
\hline Washing Machine & 41 \\
\hline
\end{tabular}

Table 2. Energy Consumption Units

\begin{tabular}{|c|c|}
\hline TIME PERIOD & GENERATED UNITS KWH \\
\hline $0000-0459$ & 390 \\
\hline $0500-0559$ & 166 \\
\hline $0600-0759$ & 126 \\
\hline $0800-0959$ & 161 \\
\hline $1000-1159$ & 143 \\
\hline $1200-1459$ & 123 \\
\hline $1500-1759$ & 102 \\
\hline $1800-1859$ & 254 \\
\hline $1900-2259$ & 446 \\
\hline $2300-2359$ & 390 \\
\hline
\end{tabular}

Accordingly, the wireless energy simulator graphical interface are divided into two panels shown in Fig 4:

- The device panel where all the daily household appliances are listed and the values are generated dynamically according to the peak hours and power.
- These values are saved to the WAMP server database for later use in JADE Agent applications.

- Graphical time-indication panel showing the night and day, off-peak and peak hours.

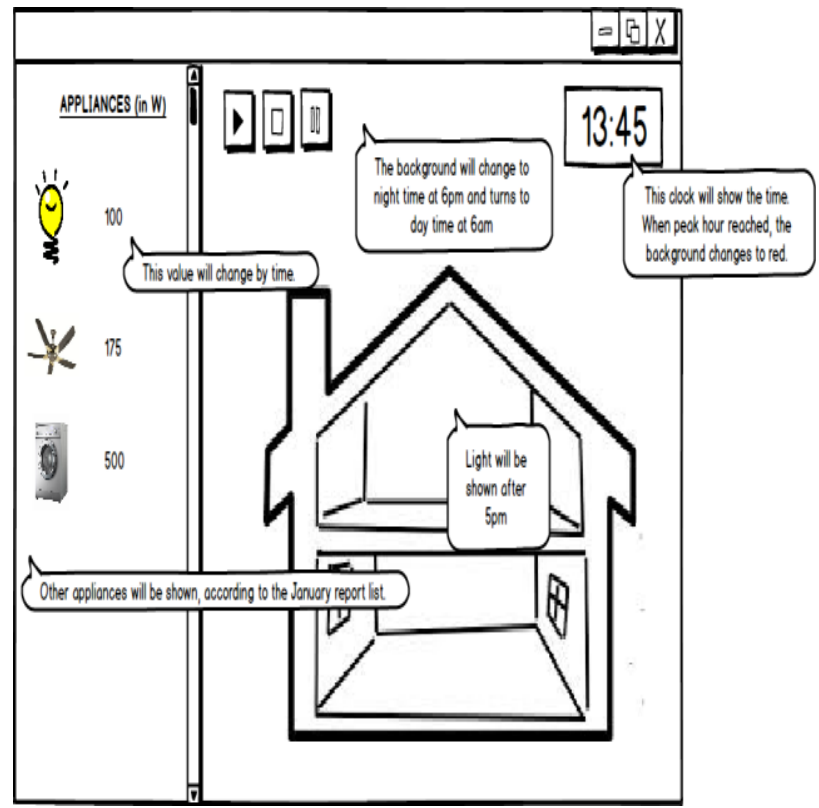

Fig.4. Wireless Energy Simulator

\section{IMPLEMENTATION USING JADE-LEAP}

The implementation of Agents in Wireless Prepaid Energy Meter carried out using JADE-LEAP Multi agent Development kit [17][18]. JADE (Java Agent Development Environment) is a full agent middleware platform.. JADE-LEAP is the only agent development kit available for mobile devices. The JADE platform is composed of agents and containers that they "live" in. The agent platform contains two default agents, Agent Management System (AMS) and directory facilitator (DF). The prior is responsible of the management of agents and the latter used to discover and manage the services an agent offers through its yellow page functionality. The agent containers can be distributed over the network. A special main container coordinates acts as the bootstrap for the JADE-LEAP platform and all other containers must register with this main container.

\section{A. Implementation of JADE Agent in DES}

The Department of Electrical Services (DES) is responsible for the operation and development in generating, transmitting and distributing electricity to the end users. Hence the DES JADE agent serves as the main container of the agent system environment which has the authority and function to kill the agents and monitor the transfer of data between all the agents in the system environment. Data such as balance units and total top up amount will go through the DES database to ensure up to date records of each household meter. These values will only be displayed in the DES main page every 5th of every month. 
The database in the DES has the function to monitor and access the data given by other JADE agents in the environment such as balance units and top-up value every 5 th of the month. To achieve the function, DES backup database will serve to store all the data before the accessed date. It contains only one table which hold the data of meter number, balance units, top-up amount and the total top-up amount to-date. The total top-up amount has the increment function whereby it increases as the user topped up as shown in the Fig 5. The DES JADE Agent will act as the main container for all the active agents in the system environment, whereby it has the feature of directory which announces available agents (Directory Facilitator) and controls the agents by creating and destroy the agents (Agent Management System) as shown in Fig 6.

Once the DES JADE Agent Management GUI as shown in Fig. 6 is started, the DES main page will also initiate. The DES main page comprises of a table stating the meter number, balance units and total top-up amount to-date

\section{B. Implementation of JADE Agent in DES}

The Department of Electrical Services (DES) is responsible for the operation and development in generating, transmitting and distributing electricity to the end users. Hence the DES JADE agent serves as the main container of the agent system environment which has the authority and function to kill the agents and monitor the transfer of data between all the agents in the system environment. Data such as balance units and total top up amount will go through the DES database to ensure up to date records of each household meter. These values will only be displayed in the DES main page every 5th of every month.

The database in the DES has the function to monitor and access the data given by other JADE agents in the environment such as balance units and top-up value every 5 th of the month. To achieve the function, DES backup database will serve to store all the data before the accessed date. It contains only one table which hold the data of meter number, balance units, top-up amount and the total top-up amount to-date. The total top-up amount has the increment function whereby it increases as the user topped up as shown in the Fig 6. The DES JADE Agent will act as the main container for all the active agents in the system environment, whereby it has the feature of directory which announces available agents (Directory Facilitator) and controls the agents by creating and destroy the agents (Agent Management System) as shown in Fig 6

Once the DES JADE Agent Management GUI as shown in Fig. 6 is started, the DES main page will also initiate. The DES main page comprises of a table stating the meter number, balance units and total top-up amount to-date.

\section{Implementation of JADE Agent in DES}

The Department of Electrical Services (DES) is responsible for the operation and development in generating, transmitting and distributing electricity to the end users. Hence the DES JADE agent serves as the main container of the agent system environment which has the authority and function to kill the agents and monitor the transfer of data between all the agents in the system environment. Data such as balance units and total top up amount will go through the DES database to ensure up to date records of each household meter. These values will only be displayed in the DES main page every 5th of every month.

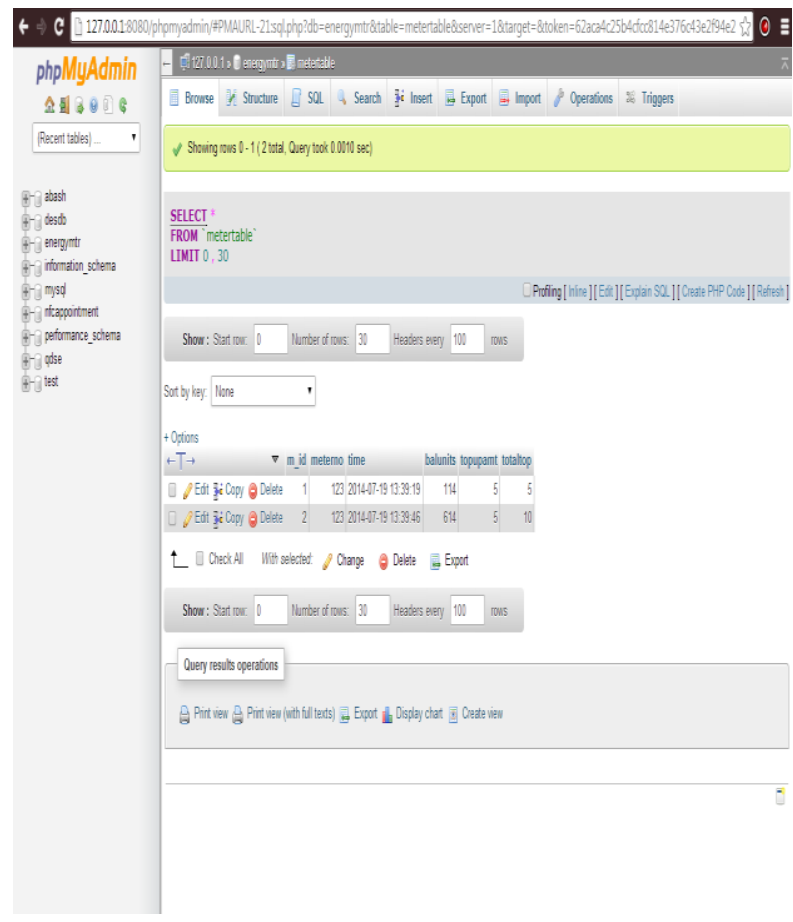

Fig.5. DES Database after Topping

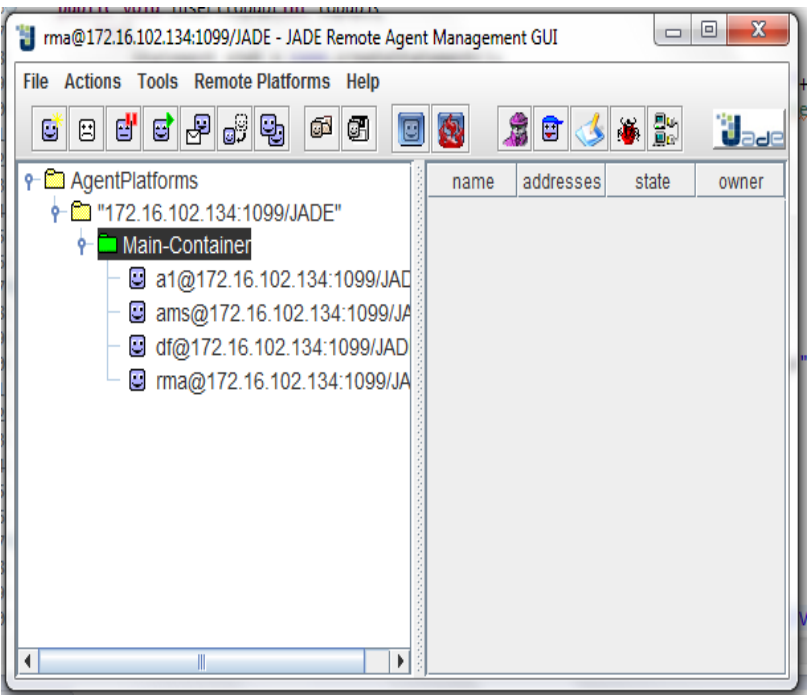

Fig.6. DES JADE Remote Management GUI

The database in the DES has the function to monitor and access the data given by other JADE agents in the environment such as balance units and top-up value every 5 th of the month. To achieve the function, DES backup database will serve to store all the data before the 
accessed date. It contains only one table which hold the data of meter number, balance units, top-up amount and the total top-up amount to-date. The total top-up amount has the increment function whereby it increases as the user topped up as shown in the Fig 5. The DES JADE Agent will act as the main container for all the active agents in the system environment, whereby it has the feature of directory which announces available agents (Directory Facilitator) and controls the agents by creating and destroy the agents (Agent Management System) as shown in Fig 6.Once the DES JADE Agent Management GUI as shown in Fig. 6 is started, the DES main page will also initiate. The DES main page comprises of a table stating the meter number, balance units and total top-up amount to-date.

\section{IMPLEMENTATION OF SMART AGENT IN WIRELESS PREPAID ENERGY METER USING JADE-LEAP}

The function of the Wireless Prepaid Meter is to display the unit consumed and balance units. The units consumed data are extracted from the Energy simulator which generates energy units based on the usage of appliances at home. The balance units are calculated inside the Wireless energy meter using the given unit consumed by the energy simulator which will be highlighted later in the next section. Login information are required to enter the Smart Agent based Wireless Prepaid energy Meter to ensure the connection to the JADE main container and to provide minimal security to the energy meter The three main functions are:

- To generate units consumed from the wireless energy meter simulator and send the values to the DES agent and User Android application.

- To calculate the balance units of each household. The balance units are calculated as:

- $\quad$ Balance units = Total balance units after topping up- units consumed

- To send a reminder to User Android application once the balance units hits certain ranges

\section{A. Implementation of Wireless Prepaid Meter using $J A D E-L E A P$}

The Smart Agent based Wireless Prepaid Meter is compiled and run on Android Emulator and login information is required for user authentication. Once logged in, the Agent based wireless prepaid meter can be connected to the DES main container by setting the energy meter IP to match with the IP address of the DES. Once this is set, the validation process begins. Fig 7 and 8 show the login page and the JADE Remote Monitoring Agent (RMA). Once the WAMP database and emulator are connected the unit consumed and balance units in the given period will be displayed on the main page. At the same time, it also communicates with the user Android application and transfers the balance units. These values will be pushed to the main container held by DES as shown in Fig.9. The refresh button will grab energy consumption units of the current time from the database as well as calculating the balance units.

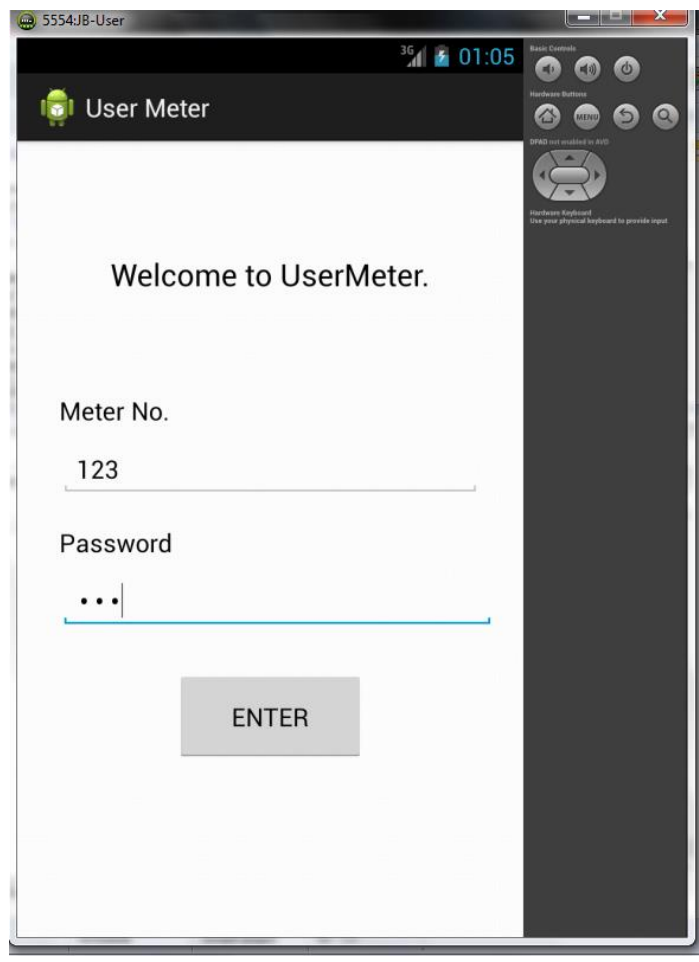

Fig.7. User Android Login

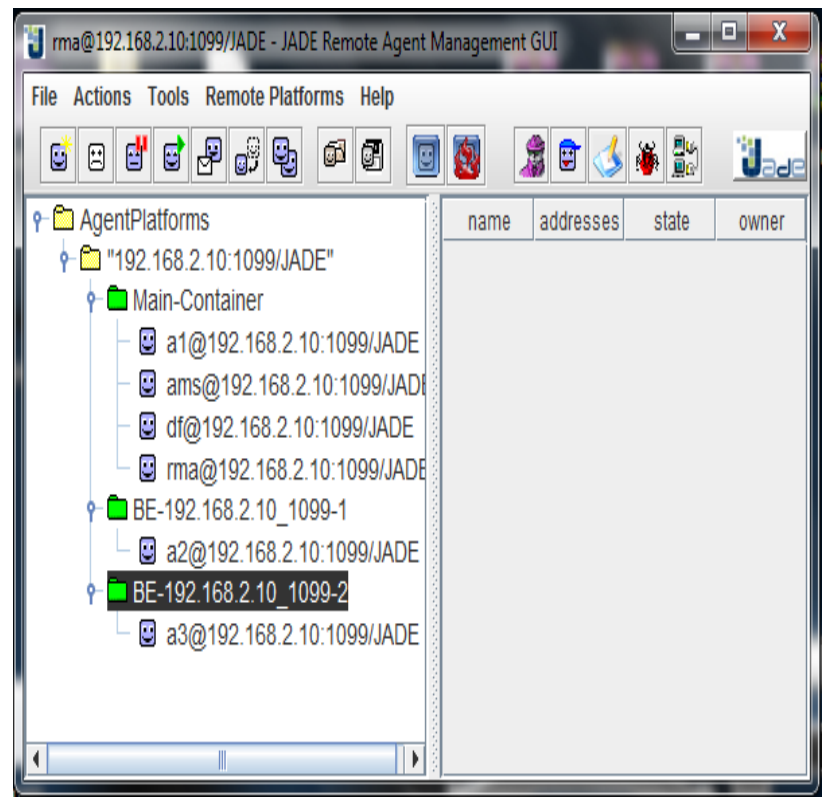

Fig.8. User Android- JADE RMA.

\section{IMPLEMENTATION OF USER ANDROID USING JADE- LEAP}

The main features of user Android application are:

- For topping up the Wireless Prepaid Meter and transfer the data to DES JADE Agent and Wireless Energy Meter JADE-LEAP Agent 
- Display the current balance units.

This serves to provide ease and mobility for the user to access their energy meter without reading the energy meter, through the help of the JADE agent's platform. This application only requires one table for storing login information. The connection to the DES Main container is established by setting the IP address of the User Android Application JADE-LEAP to match with that of the DES's IP address. Once they are set to match it creates a pathway to transfer the top-up amount for the DES Agent and receive the balance units form the Wireless Prepaid Meter Agent as shown in Fig. 9. The User Android Application requires user to login to their meter information before accessing the application. Once authenticated, the application will automatically connect to the DES JADE Main container.

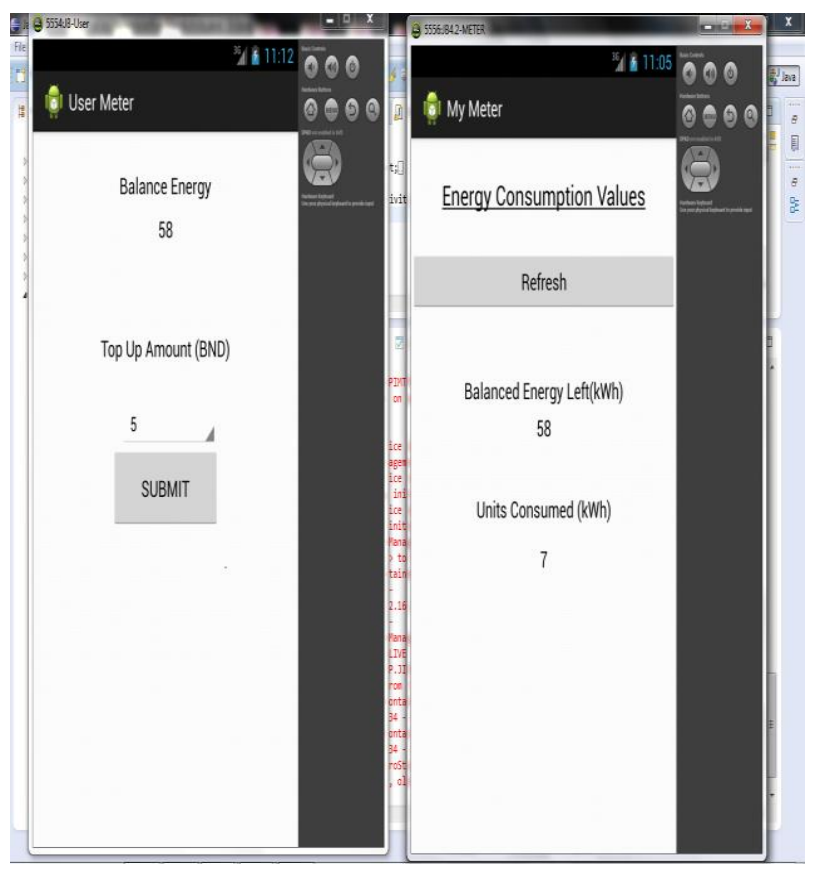

Fig.9. Communication between Wireless Meter and User Android Application

Once validated, the application will display the current balance units and top-up amount options (i.e. BND5, BND10, BND30 and BND100) as shown in Table 3. If top-up amount is selected, the balance unit value will increase according to the top-up value stated. An alert will initiate after topping up to inform the user as shown in Fig. 10

In addition, when the balance unit hits certain range, an alert stating low balance will be displayed as shown in Fig 11.. That is when balance hits 300 units, first reminder sent. Following the reminder if no action from user, once balance touches 200 units second reminder and third reminder once balance touches 100 units. If no action from user for the reminder, automatically power outlet be cut off once balance units not enough for providing power. Fig. 12 shows the balance after topping up.

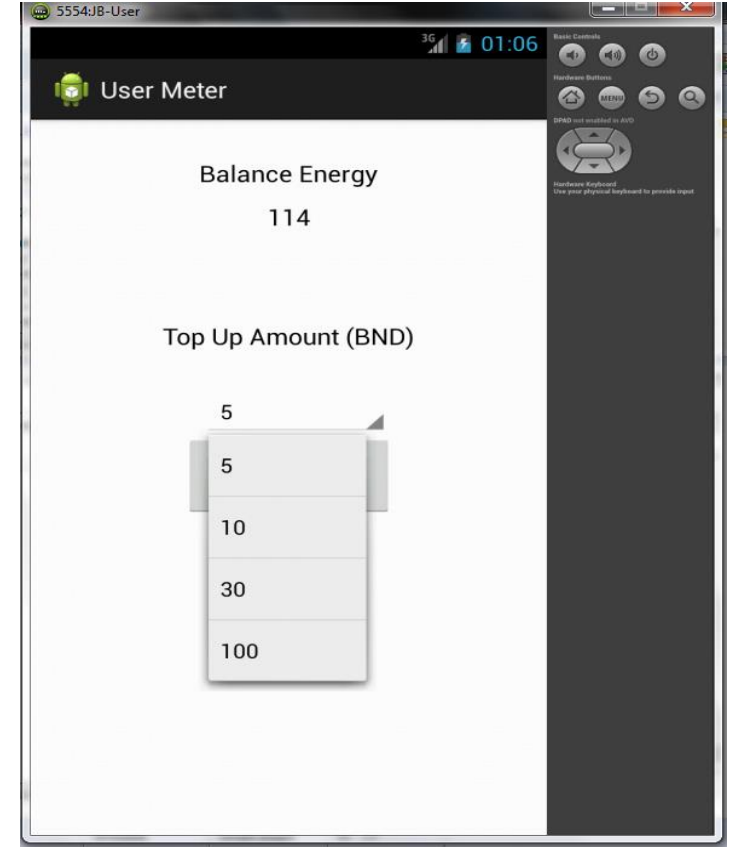

Fig.10. User Android with Balance Energy and Top up

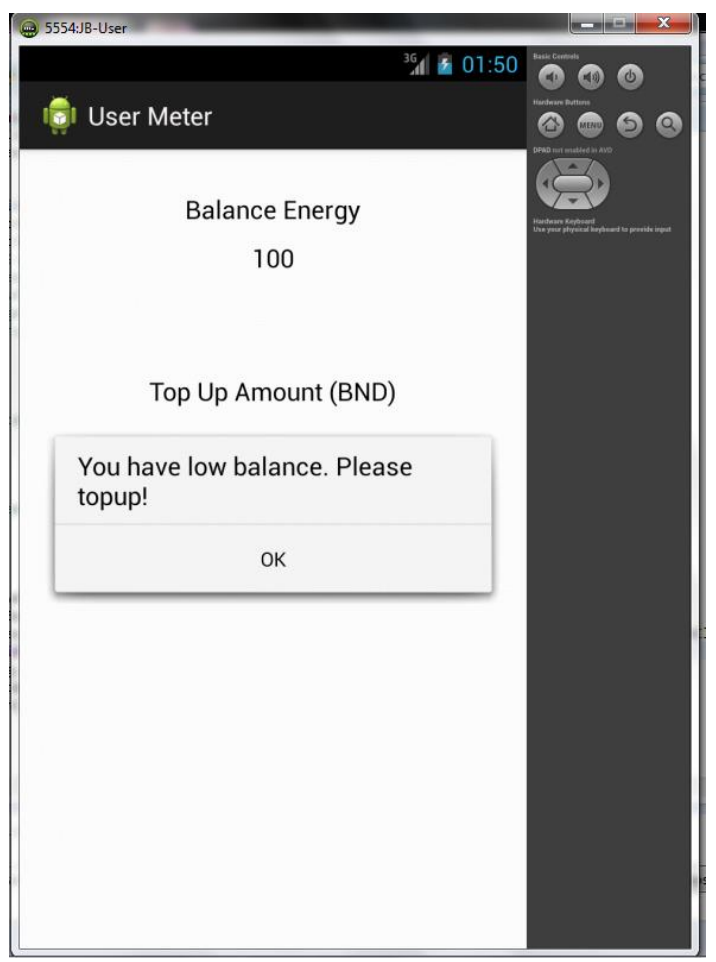

Fig.11. Top Up Alert

Table 3. Top Up Values

\begin{tabular}{|c|c|}
\hline Topup value & Units \\
\hline BND 5 & 500 \\
\hline BND 10 & 650 \\
\hline BND 30 & 900 \\
\hline BND 100 & 1175 \\
\hline
\end{tabular}




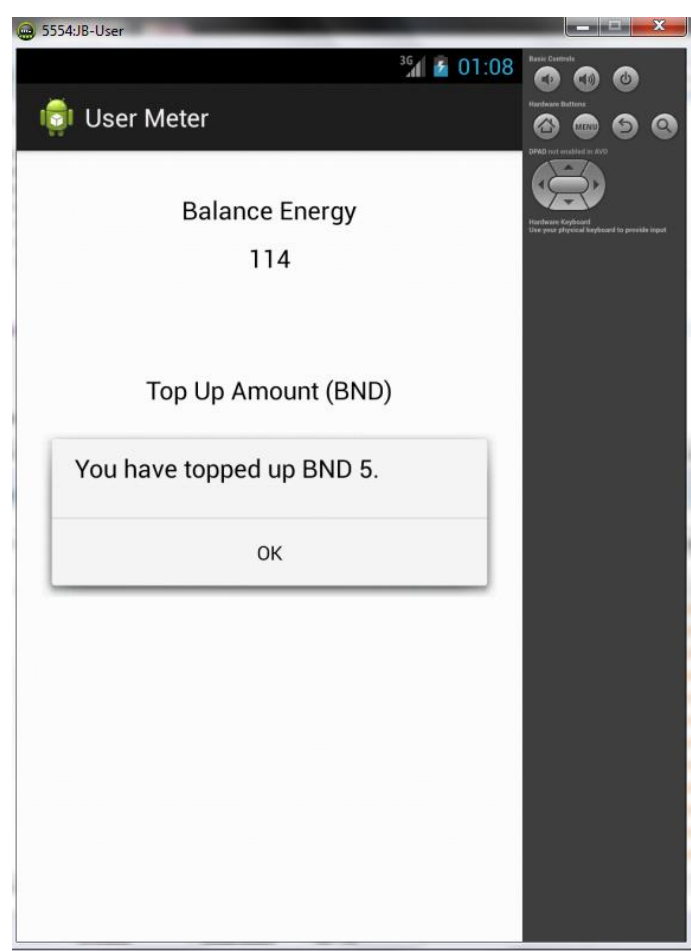

Fig.12. Balance After Top Up

\section{CONCLUSION \& FUTURE WORK}

Brunei Darussalam is engaging technologies in order to move forward in every facet in the country to create a knowledge society and it is no exception to the Department of Electrical Services (DES) in the energy sectors. The introduction of prepaid meter (PM) has solved many issues in the DES and it also cuts down the hassle of having to visit households to read meters, which can be a big challenge. However PM offers and opens up many opportunities for further improvement. For example, DES do not have real time information on how energy units are consumed, balance units for each household and how users spend on energy usage on a regular basis. And we proposed and developed a prototype Wireless Smart Power Meter using Agent technologies of the JADE and JADE-LEAP running on Android Jelly Bean mobile platform with Eclipse Juno IDE by creating three agents. We were able to demonstrate the capability of the services and the intelligence of this multi-agent environment of the proposed system. The system was able to transfer and query energy units in real time without the help of any human interactions, thus easing the monitoring process. In future the system proposes to integrate other features like sending reminders based on rate of energy units used. In addition computing energy units based on tariff rate, top up amount and taking into amount of energy used towards energy conservation. Last but not least adding the energy units to energy meter from energy department based on top up from user.

\section{REFERENCES}

[1] Y. Merlin and P. E. Sankaranarayanan, "Accessing
Remote Energy Meters Using Software Agents." Proceedings of IEEE Electro/Information Technology. Rochester, USA, 2001.

[2] C D. Suriyakala, and P.E. Sankaranarayanan, "Remote Accessing of Intelligent Energy Meter,"5th International Conference on Trends in Industrial Measurements and Automation, Tiruchirapally, TamilNadu, India, 2007

[3] C.D.Suriyakala and P.E. Sankaranarayan, "Intelligent agent system for accessing remote energy meters." Proceedings of 1 st International conference Digital Communications \& Computer Applications, Jordan, 2007.

[4] C.D. Suriyakala and P.E. Sankaranarayanan,"Smart Multi Agent Architecture for Congestion control to Access Remote Energy Meters", Proceedings of IEEE International Conference on Computational Intelligence and Multimedia Applications. Sivakasi, Tamilnadu, India, 2007.

[5] C.D. Suriyakala, "Studies on the Application of Software Agents for Accessing Energy Meter Data through Power Line Communication,“ Ph.d Thesis, Sathyabama University, Chennai, India, 2009

[6] R. Tahboub, D. Lazarescu and V. Lazarescu. "Modeling and Simulation of Secure Automatic Energy Meter Reading and Management Systems using Mobile Agents", International Journal of Computer and Network Security, Vol.7, No.1, pp.244-253, 2007.

[7] T. Jamil. "Design and Implementation of a Wireless Automatic Meter Reading System”, Proceedings of world Congress on Engineering, London, UK, 2008

[8] C. Tatsiopoulos and A. Ktena, "A Smart ZIGBEE Based Wireless Sensor Meter System", 16th International Conference on Systems, Signals and Image Processing (IWSSIP), Chalkida, Greece, 2009.

[9] N. Kommu, P.Nagamani and M.Kollam, "Designing of an Automated Power Meter Reading with Zigbee Communication", International Journal of Computer and Communication Technology, Vol.2(7), pp.13-16, 2011

[10] A.H. Primicanta, M.Y Nayan and M Awan, "ZigBeeGSM based Automatic Meter Reading system", 2010 International Conference on Intelligent and Advanced Systems (ICIAS), Kuala Lumpur, Malaysia, 2010

[11] H.C. Chen and L.Y Chang, "Design and Implementation of a ZigBee-Based Wireless Automatic Meter Reading System”, PRZEGLĄD ELEKTROTECHNICZNY (Electrical Review), Vol.88(1b), pp. 64-68, 2012

[12] L. Q. Xi and Li. Gang. "Design of remote automatic meter reading system based on ZigBee and GPRS", Proceedings of Third International Symposium on Computer Science and Computational Technology(ISCSCT '10), Jiaozuo, P. R. China, 2010

[13] A. Jain and M. Bagree, "A Prepaid Meter using Mobile communication", International Journal of Engineering, Science and Technology, Vol.3(3), 160-166, 2011

[14] B.O.Omijeh and G.I.Ighalo. "Modelling of GSM based Energy Recharge Scheme for Prepaid Meter", IOSR Journal of Electrical and Electronics Engineering, Vol.4(1), 46-53, 2013

[15] M.Jebashanthini , A Sweety , R Rini and A. Kirubaraj, "Advanced Prepaid Energy Metering using GSM", Indian Streams Research Journal, 2013

[16] A.T.Wan, S. Suresh and S.N. Binti Sait, "Smart Agent based Prepaid Wireless Energy Meter", Accepted in IEEE International conference on Cloud Computing and Internet of Things, Changchun, China, December 13-14, 2014

[17] F. Bellifemine, G. Caire, G and D. Greenwood," Developing multi-agent system with jade. Chichester, UK: 
John Wiley \& Sons, 2007.

[18] F. Bellifemine, G. Caire, A. Poggi and G. Rimassa, "Jade: A white paper. EXP in Search of Innovation, 3(3), 6-19, 2003.

[19] C D, Suriyakala, and P.E. Sankaranarayanan,. "Spread Spectrum Techniques for Power Line Communication" in Asian journal of Information Technology, Vol. 5(10), pp. 1131-1136,2006.

[20] C D, Suriyakala, and P.E.Sankaranarayana,. "Study on Bit Error Rate Performance of OFDM and CDMA Techniques for Power Line Communication". 4th International conference in Computer Science and Application, SanDiego, California, 2006

[21] C D, Suriyakala, and P.E.Sankaranarayana,. Spread Spectrum Techniques for an Intelligent Energy Meter" International journal of business data for communications and Networking, Vol.3(3), pp 57-68, 2007.

[22] C.D.Suriyakala, and P.E. Sankaranarayanan, "Intelligent Energy Meter" ICT for National Development, The 40th Annual National Convention of Computer Society of India, Hyderabad, 2005

[23] S Safaric , K Malaric,. "ZigBee Wireless Standard", Proc. of the 48th International Symposium ELMAR-2006, Zadar Croatia.

[24] C. Tatsiopoulos and A. Ktena, "A Smart ZIGBEE Based Wireless Sensor Meter System", 16th International Conference on Systems, Signals and Image Processing (IWSSIP), Chalkida, Greece, 2009.

[25] M.M. Haque, M.K. Hossain and M.M. Ali, M.R Islam Sheikh. "Microcontroller Based Single Phase Digital Prepaid Energy Meter for Improved Metering and Billing System", International Journal of Power Electronics and Drive systems, Vol.1(2), 139-147,2011.

[26] S.Suresh and A.T. Wan. "ABASH, Android based smart home monitoring using wireless sensors."Proceedings of IEEE Conference on Clean Energy and Technology (CEAT), Langkawai, Malaysia, Nov 18-20 2013. Pp 494499.

\section{Authors' Profiles}

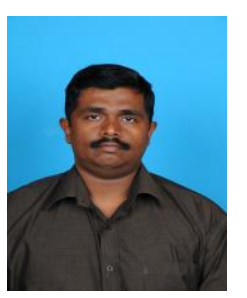

Prof. (Dr) $\mathbf{S}$ Suresh is an Associate Professor, Department of Information Technology, SRM University. $\mathrm{He}$ is also Senior Member of IEEE computer Society and Computer Society of India too. He has supervised more than 30 research students leading to M.Sc, ME, M.Phil and M.S degrees and currently supervising 3 students leading to M.phil and Ph.d in UWI, Jamaica and a doctoral student in Institut Teknologi Brunei respectively. He has got to his credit, as on date, more than 70 fully refereed research papers published in the Proceedings of major IEEE international conferences, as Book Chapters and in International Journals with citation of 287 and H-index of 9 . He is also a Reviewer and Technical Committee member for a number of IEEE Conferences and Journals. He has conducted many tutorials, workshops and also given Guest Lectures in networking in various Universities and Colleges.. He also had collaborative and funded research during 2008-2010 in University of WestIndies, Jamaica. He currently has a Funded project in energy where he is principal investigator. His current research interests are mainly towards 'Mobile and Ubiquitous Computing - Wireless Sensor Networks, RFID, Cloud Computing, Internet of Things, Network Congestion in wired \& wireless networks used in the Health, Commercial and Engineering sectors

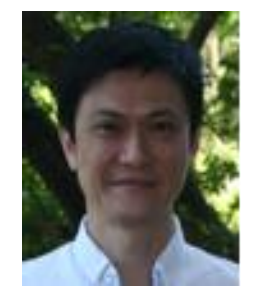

Dr. Au is a Senior Lecturer and the Dean at the School of Computing and Informatics, Institut Teknologi Brunei (ITB). He earned his BEng from University of Glasgow, UK, MSc in Data Communications Systems from Brunel University, UK, and most recently $\mathrm{PhD}$ from University of Queensland, Australia in 2013. Dr. Au is also the head of IOT research cluster at ITB. His most recent research includes using sensors for house monitoring based on Android system, Intelligent Agent System and eLearning experiential learning

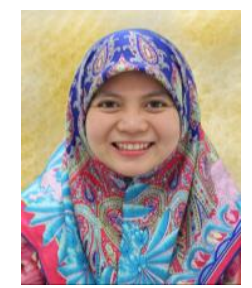

Siti Nurafifah binti Sait holds Bachelor Degree (Hons) in Internet Computing from School of Computing and Informatics, Institut Teknologi Brunei in 2014. Her final year Bachelor (Hons) was on mobile patient appointment system using NFC which resulted in IEEE Conference proceeding and Journal. She also worked as Research Assistant on Research project pertaining to wireless Smart Prepaid energy Meter towards Agent development which resulted in one paper accepted in conference. Currently she is working as a Lecturer in Brunei Polytechnic. She also possess programming skills in Java, Php, Android and JADE-LEAP Agent Development Kit. Her research interests are mainly in Mobile Health, Smart Energy, Mobile computing.

How to cite this paper: Suresh Sankaranarayanan, $\mathrm{Au}$ Thien Wan, Nurafifah binti Sait, "Application of Intelligent Agents in Wireless Prepaid Energy Meter", International Journal of Intelligent Systems and Applications (IJISA), Vol.8, No.3, pp.66-76, 2016. DOI: 10.5815/ijisa.2016.03.08 